\section{Healthcare in Low-Resource Settings: the long view for healthcare}

\author{
Abiola Fasina \\ Henry Jackson Foundation/U.S. Military \\ HIV Research Program, Bethesda, MD, \\ USA
}

It is with great pleasure and gratitude that I commence my two-year appointment as Editorin-Chief for Healthcare in Low Resource Settings (HLS). Recent events have demonstrated the interconnectedness of our world. A patient with Ebola from West Africa ended up in New York City after riding the subway. Information is dispersed within minutes through the Internet and social media. The Brexit vote affected global financial markets. This era calls for a wily adaptability in healthcare as we try to understand and synthesize disparate streams of information and integrate them into practice. It also affords the opportunity to harness technology in new ways to solve age-old health problems. In such changing times, how can HLS prove to be relevant?

I submit that the way forward is to attend to our initial mandate with renewed vigor. Currently, no forum successfully blends the voices and experience of researchers from both developing and developed worlds in an equitable way. The current nature of academic publishing favors increased productivity from those based in high-resource countries by virtue of improved access to robust institutional support for research and better funding. That this journal is Open Access increases its reach in low-resource settings but more must be done to understand all viewpoints in order to develop effective outcomes. It is vitally important that those who live and work in lowresource settings are instrumental in the proposal and development of their own solutions. Barriers to hearing their voices need to be actively overcome by collective will.

Our Journal will focus on the following strategic targets over the next two years: increased publication of work resulting from multi-disciplinary collaboration between researchers in high and low-resource settings; adaption of our current format to improve access for those in low bandwidth low-resource countries where large streaming content is difficult to view; a review of the Editorial Board with greater inclusion of researchers from lowresource settings, if they are currently underrepresented; increased efforts to highlight the work of early and mid-career professionals in both settings with an interest in issues pertinent to low-resource settings; a renewed focus on ethics and policy around work in lowresource settings; highlighting and publishing research focused on innovative and disruptive technology that can be harnessed towards low-
Correspondence: Abiola Fasina, Henry Jackson Foundation/U.S. Military HIV Research Program, 6720A Rockledge Drive, Suite 400, 20817 Bethesda, MD, USA.

Tel: +1.301 .500 .3600 - Fax: +1.301 .500 .3666 .

E-mail: abiola.fasina@gmail.com

Key words: Healthcare in Low-Resource Settings; Multi-disciplinarity; Technology; PAGEPress.

Received for publication: 17 November 2016. Accepted for publication: 27 November 2016.

This work is licensed under a Creative Commons Attribution 4.0 License (by-nc 4.0).

(C) Copyright A. Fasina, 2016

Licensee PAGEPress, Italy

Healthcare in Low-resource Settings 2016; 4:6396 doi:10.4081/hls.2016.6396

resource settings for more effective healthcare outcomes.

These ideas are not new but I believe they represent a subtle recalibration in the way in which knowledge is solicited and disseminated with respect to low-resource settings. In today's world, information flows in so many directions that the two-way street idiom is obsolete. We have much to learn from each when there is a forum to communicate and HLS intends to play a key role in that discussion. 